\title{
MINIMUM DOMINATING DISTANCE ENERGY OF A GRAPH
}

\author{
M.R. Rajesh Kanna ${ }^{1}$, B.N. Dharmendra ${ }^{1}$, And G. SRidhara ${ }^{1,2}$ \\ ${ }^{1}$ Post Graduate Department of Mathematics, Maharani's Science College for \\ Women, J.L.B. Road, Mysore - 570 005, India \\ mr.rajeshkanna@gmail.com, bndharma@gmail.com \\ ${ }^{2}$ Research Scholar, Research and Development Centre, Bharathiar \\ University, Coimbatore 641 046, India, \\ srsrig@gmail.com
}

\begin{abstract}
Recently we introduced the concept of minimum dominating energy [19]. Motivated by this paper, we introduced the concept of minimum dominating distance energy $E_{D d}(G)$ of a graph $G$ and computed minimum dominating distance energies of a star graph, complete graph, crown graph and cocktail party graphs. Upper and lower bounds for $E_{D d}(G)$ are also established.

Key words and Phrases: Minimum dominating set, dominating distance matrix, dominating distance eigenvalues, dominating distance energy.
\end{abstract}

\begin{abstract}
Abstrak. Pada paper sebelumnya pada tahun 2013, kami telah memperkenalkan konsep energi pendominasi minimum. Kami melanjutkan konsep tersebut dengan memperkenalkan konsep energi jarak pendominasi minimum $E_{D d}(G)$ dari suatu graf $G$ dan menghitung energi jarak pendominasi minimum dari graf bintang, graf lengkap, graf mahkota, dan graf cocktail party. Kami juga mendapatkan batas atas dan bawah untuk $E_{D d}(G)$.

Kata kunci: Himpunan pendominasi minimum, matriks jarak pendominasi, nilai eigen jarak pendominasi, energi jarak pendominasi.
\end{abstract}

\section{INTRODUCTION}

The concept of energy of a graph was introduced by I. Gutman [9] in the year 1978. Let $G$ be a graph with $n$ vertices $\left\{v_{1}, v_{2}, \ldots, v_{n}\right\}$ and $m$ edges. Let $A=\left(a_{i j}\right)$ be the adjacency matrix of the graph. The eigenvalues $\lambda_{1}, \lambda_{2}, \cdots, \lambda_{n}$ of $A$, assumed in non increasing order, are the eigenvalues of the graph $G$. As $A$ is

2000 Mathematics Subject Classification: Primary 05C50, 05C69.

Received: 16-07-2013, revised: 24-01-2014, accepted: 25-01-2014. 
real symmetric, the eigenvalues of $G$ are real with sum equal to zero. The energy $E(G)$ of $G$ is defined to be the sum of the absolute values of the eigenvalues of $G$. i.e.,

$$
E(G)=\sum_{i=1}^{n}\left|\lambda_{i}\right| .
$$

For details on the mathematical aspects of the theory of graph energy see the reviews[10], paper [11] and the references cited there in. The basic properties including various upper and lower bounds for energy of a graph have been established in [16], and it has found remarkable chemical applications in the molecular orbital theory of conjugated molecules [5, 6, 7, 12].

Further, studies on maximum degree energy, minimum dominating energy, Laplacian minimum dominating energy, minimum covering distance energies can be found in $[18,19,20,21]$ and the references cited there in.

The distance matrix of $G$ is the square matrix of order $n$ whose $(i, j)$ - entry is the distance (= length of the shortest path) between the vertices $v_{i}$ and $v_{j}$. Let $\rho_{1}, \rho_{2}, \ldots, \rho_{n}$ be the eigenvalues of the distance matrix of $G$. The distance energy $D E$ is defined by

$$
D E=D E(G):=\sum_{i=1}^{n}\left|\rho_{i}\right| .
$$

Detailed studies on distance energy can be found in $[3,4,8,13,14,22]$.

\section{The Minimum Dominating Distance Energy}

Let $G$ be a simple graph of order $n$ with vertex set $V=\left\{v_{1}, v_{2}, \ldots, v_{n}\right\}$ and edge set $E$. A subset $D$ of $V$ is called a dominating set of $G$ if every vertex of $V$ - $D$ is adjacent to some vertex in $D$. Any dominating set with minimum cardinality is called a minimum dominating set. Let $D$ be a minimum dominating set of a graph $G$. The minimum dominating distance matrix of $G$ is the $n \times n$ matrix defined by $A_{D d}(G):=\left(d_{i j}\right)$, where

$$
d_{i j}= \begin{cases}1 & \text { if } i=j \text { and } v_{i} \in D \\ d\left(v_{i}, v_{j}\right) & \text { otherwise }\end{cases}
$$

The characteristic polynomial of $A_{D d}(G)$ is denoted by $f_{n}(G, \rho)=\operatorname{det}(\rho I-$ $\left.A_{D d}(G)\right)$. The minimum dominating eigenvalues of the graph $G$ are the eigenvalues of $A_{D d}(G)$. Since $A_{D d}(G)$ is real and symmetric, its eigenvalues are real numbers and we label them in non-increasing order $\rho_{1} \geqslant \rho_{2} \geqslant \cdots \geqslant \rho_{n}$. The minimum dominating energy of $G$ is defined as

$$
E_{D d}(G):=\sum_{i=1}^{n}\left|\rho_{i}\right|
$$

Note that the trace of $A_{D d}(G)=$ Domination Number $=k$.

Example 1. The possible minimum dominating sets for the following graph $G$ in Figure 1 are i) $D_{1}=\left\{v_{1}, v_{5}\right\}$, ii) $D_{2}=\left\{v_{2}, v_{5}\right\}$, iii) $D_{3}=\left\{v_{2}, v_{6}\right\}$ 


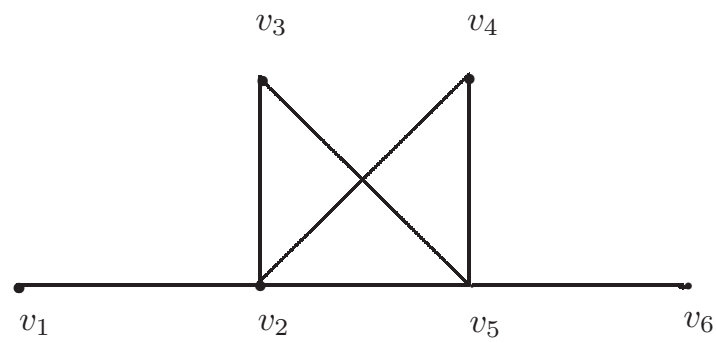

Figure 1

i) $A_{D d_{1}}(G)=\left(\begin{array}{cccccc}1 & 1 & 2 & 2 & 2 & 3 \\ 1 & 0 & 1 & 1 & 1 & 2 \\ 2 & 1 & 0 & 2 & 1 & 2 \\ 2 & 1 & 2 & 0 & 1 & 2 \\ 2 & 1 & 1 & 1 & 1 & 1 \\ 3 & 2 & 2 & 2 & 1 & 0\end{array}\right)$

Characteristic equation is $\rho^{6}-2 \rho^{5}-43 \rho^{4}-114 \rho^{3}-94 \rho^{2}-8 \rho+8=0$. Minimum dominating distance eigenvalues are $\rho_{1} \approx-3.0257, \rho_{2} \approx-2, \rho_{3} \approx-1.3386, \rho_{4} \approx$ $-0.5067, \rho_{5} \approx 0.2255, \rho_{6} \approx 8.6456$. Minimum dominating distance energy, $E_{D d_{1}}(G) \approx$ 15.7420

ii) $A_{D d_{2}}(G)=\left(\begin{array}{cccccc}0 & 1 & 2 & 2 & 2 & 3 \\ 1 & 1 & 1 & 1 & 1 & 2 \\ 2 & 1 & 0 & 2 & 1 & 2 \\ 2 & 1 & 2 & 0 & 1 & 2 \\ 2 & 1 & 1 & 1 & 1 & 1 \\ 3 & 2 & 2 & 2 & 1 & 0\end{array}\right)$

Characteristic equation is $\rho^{6}-2 \rho^{5}-43 \rho^{4}-100 \rho^{3}-41 \rho^{2}+36 \rho-4=0$. Minimum dominating distance eigen values are $\rho_{1} \approx-3.3028, \rho_{2} \approx-2, \rho_{3} \approx-1.6445, \rho_{4} \approx$ $0.1431, \rho_{5} \approx 0.3028, \rho_{6} \approx 8.5015$. Minimum dominating distance energy, $E_{D d_{2}}(G) \approx$ 15.8946. Therefore, minimum dominating distance energy depends on the dominating set. 


\section{Minimum Dominating Distance Energy of Some Standard Graphs}

Definition 3.1. The cocktail party graph, is denoted by $K_{n \times 2}$, is a graph having the vertex set $V=\bigcup_{i=1}^{n}\left\{u_{i}, v_{i}\right\}$ and the edge set $E=\left\{u_{i} u_{j}, v_{i} v_{j}: i \neq j\right\} \bigcup\left\{u_{i} v_{j}, v_{i} u_{j}\right.$ : $1 \leq i<j \leq n\}$.

Theorem 3.2. The minimum dominating distance energy of cocktail party graph $K_{n \times 2}$ is $4 n$.

Proof. Let $K_{n \times 2}$ be the cocktail party graph with vertex set $V=\bigcup_{i=1}^{n}\left\{u_{i}, v_{i}\right\}$. The minimum dominating set of $K_{n \times 2}$ is $D=\left\{u_{1}, v_{1}\right\}$. Then

$$
A_{D d}\left(K_{n \times 2}\right)=\left(\begin{array}{ccccccccc}
1 & 2 & 1 & 1 & \ldots & 1 & 1 & 1 & 1 \\
2 & 1 & 1 & 1 & \ldots & 1 & 1 & 1 & 1 \\
1 & 1 & 0 & 2 & \ldots & 1 & 1 & 1 & 1 \\
1 & 1 & 2 & 0 & \ldots & 1 & 1 & 1 & 1 \\
\vdots & \vdots & \vdots & \vdots & \ddots & \vdots & \vdots & \vdots & \vdots \\
1 & 1 & 1 & 1 & \ldots & 0 & 2 & 1 & 1 \\
1 & 1 & 1 & 1 & \ldots & 2 & 0 & 1 & 1 \\
1 & 1 & 1 & 1 & \ldots & 1 & 1 & 0 & 2 \\
1 & 1 & 1 & 1 & \ldots & 1 & 1 & 2 & 0
\end{array}\right)
$$

Characteristic equation is $\rho^{n-2}(\rho+1)(\rho+2)^{(n-1)}\left[\rho^{2}-(2 n+1) \rho+(2 n-2)\right]=0$ Minimum dominating distance eigenvalues are $\rho=0[(n-2)$ times], $\rho=-1$ [one time], $\rho=-2\left[(n-1)\right.$ times], $\rho=\frac{(2 n+1) \pm \sqrt{4 n^{2}-4 n+9}}{2}$ [one time each]. So, minimum dominating distance energy is $E_{D d}\left(\underset{K_{n \times 2}}{2}\right)=4 n$

Theorem 3.3. For any integer $n \geq 3$, the minimum dominating distance energy of star graph $K_{1, n-1}$ is equal to $4 n-7$.

Proof. Consider the star graph $K_{1, n-1}$ with vertex set $V=\left\{v_{0}, v_{1}, v_{2}, \ldots, v_{n-1}\right\}$, where $\operatorname{deg}\left(v_{0}\right)=n-1$. Minimum dominating set $D=\left\{v_{0}\right\}$. Then

$$
A_{D d}\left(K_{1, n-1}\right)=\left(\begin{array}{ccccc}
1 & 1 & 1 & \ldots & 1 \\
1 & 0 & 2 & \ldots & 2 \\
1 & 2 & 0 & \ldots & 2 \\
\vdots & \vdots & \vdots & \ddots & \vdots \\
1 & 2 & 2 & \ldots & 0
\end{array}\right)_{n \times n}
$$

Characteristic equation is $(\rho+2)^{n-2}\left(\rho^{2}-(2 n-3) \rho+(n-3)\right)=0$ 
The minimum dominating distance eigenvalues are $\rho=-2[(\mathrm{n}-2)$ times $], \rho=$ $\frac{(2 n-3) \pm \sqrt{4 n^{2}-16 n+21}}{2}$ [one time each]. So, minimum dominating distance energy is $E_{D d}\left(K_{1, n-1}\right)=4 n-7$.

Definition 3.4. The crown graph $S_{n}^{0}$ for an integer $n \geq 2$ is the graph with vertex set $\left\{u_{1}, u_{2}, \ldots, u_{n}, v_{1}, v_{2}, \ldots, v_{n}\right\}$ and edge set $\left\{u_{i} v_{j}: 1 \leq i, j \leq n, i \neq j\right\}$. Hence $S_{n}^{0}$ coincides with the complete bipartite graph $K_{n, n}$ with horizontal edges removed.

Theorem 3.5. For any integer $n \geq 2$, the minimum dominating distance energy of the crown graph $S_{n}^{0}$ is equal to

$$
7(n-1)+\sqrt{n^{2}-2 n+5} .
$$

Proof. For the crown graph $S_{n}^{0}$ with vertex set $V=\left\{u_{1}, u_{2}, \ldots, u_{n}, v_{1}, v_{2}, \ldots, v_{n}\right\}$, minimum dominating set is $D=\left\{u_{1}, v_{1}\right\}$. Then

$$
A_{D d}\left(S_{n}^{0}\right)=\left(\begin{array}{cccccccccc}
1 & 2 & 2 & \ldots & 2 & 3 & 1 & 1 & \ldots & 1 \\
2 & 0 & 2 & \ldots & 2 & 1 & 3 & 1 & \ldots & 1 \\
2 & 2 & 0 & \ldots & 2 & 1 & 1 & 3 & \ldots & 1 \\
\vdots & \vdots & \vdots & \ddots & \vdots & \vdots & \vdots & \vdots & \ddots & \vdots \\
2 & 2 & 2 & \ldots & 0 & 1 & 1 & 1 & \ldots & 3 \\
3 & 1 & 1 & \ldots & 1 & 1 & 2 & 2 & \ldots & 2 \\
1 & 3 & 1 & \ldots & 1 & 2 & 0 & 2 & \ldots & 2 \\
1 & 1 & 3 & \ldots & 1 & 2 & 2 & 0 & \ldots & 2 \\
\vdots & \vdots & \vdots & \ddots & \vdots & \vdots & \vdots & \vdots & \ddots & \vdots \\
1 & 1 & 1 & \ldots & 3 & 2 & 2 & 2 & \ldots & 0
\end{array}\right)_{(2 n \times 2 n)}
$$

Characteristic equation is

$$
\rho^{n-2}(\rho+4)^{n-2}\left[\left(\rho^{2}+(7-n) \rho+(11-3 n)\right]\left[\rho^{2}-(3 n+1) \rho+(3 n-3)\right]=0\right.
$$

Minimum dominating distance eigenvalues are $\rho=0[(n-2)$ times $], \rho=-4 \quad[(n-$ 2)times] $\rho=\frac{(n-7) \pm \sqrt{n^{2}-2 n+5}}{2}$, [one time each], $\rho=\frac{(3 n+1) \pm \sqrt{9 n^{2}-6 n+13}}{2}$ [one time each]. So, minimum dominating distance energy is

$$
E_{D d}\left(S_{n}^{0}\right)=7(n-1)+\sqrt{n^{2}-2 n+5} .
$$

Theorem 3.6. For any integer $n \geq 2$, the minimum dominating distance energy of complete graph $K_{n}$ is $(n-2)+\sqrt{n^{2}-2 n+5}$.

Proof. For complete graphs the minimum dominating distance matrix is same as minimum dominating matrix [19], therefore the minimum dominating distance energy is equal to minimum dominating energy. 


\section{Properties of Minimum Dominating Eigenvalues}

Theorem 4.1. Let $G$ be a simple graph with vertex set $V=\left\{v_{1}, v_{2}, \ldots, v_{n}\right\}$, edge set $E$ and $D=\left\{u_{1}, u_{2}, \ldots, u_{k}\right\}$ be a minimum dominating set. If $\rho_{1}, \rho_{2}, \ldots, \rho_{n}$ are the eigenvalues of minimum dominating distance matrix $A_{D d}(G)$ then

(i) $\sum_{i=1}^{n} \rho_{i}=|D|$

(ii) $\sum_{i=1}^{n} \rho_{i}^{2}=2 m+2 M+|D|$ where $M=\sum_{i<j, d\left(v_{i}, v_{j}\right) \neq 1} d\left(v_{i}, v_{j}\right)^{2}$ and $m=|E|$.

Proof. i) We know that the sum of the eigenvalues of $A_{D d}(G)$ is the trace of $A_{D d}(G)$. Therefore,

$$
\sum_{i=1}^{n} \rho_{i}=\sum_{i=1}^{n} d_{i i}=|D|=k
$$

(ii) Similarly, the sum of squares of the eigenvalues of $A_{D d}(G)$ is trace of $\left[A_{D d}(G)\right]^{2}$ Therefore,

$$
\begin{aligned}
\sum_{i=1}^{n} \rho_{i}^{2} & =\sum_{i=1}^{n} \sum_{j=1}^{n} d_{i j} d_{j i} \\
& =\sum_{i=1}^{n}\left(d_{i i}\right)^{2}+\sum_{i \neq j} d_{i j} d_{j i} \\
& =\sum_{i=1}^{n}\left(d_{i i}\right)^{2}+2 \sum_{i<j}\left(d_{i j}\right)^{2} \\
& =|D|+2 \sum_{i<j} d\left(v_{i}, v_{j}\right)^{2} \\
& =k+2 m+2 M \quad \text { where } M=\sum_{i<j, d\left(v_{i}, v_{j}\right) \neq 1} d\left(v_{i}, v_{j}\right)^{2}
\end{aligned}
$$

Corollary 4.2. Let $G$ be a $(n, m)$ simple graph with diameter 2 and $D=\left\{u_{1}, u_{2}, \ldots, u_{k}\right\}$ be a minimum dominating set. If $\rho_{1}, \rho_{2}, \ldots, \rho_{n}$ are the eigenvalues of minimum dominating distance matrix $A_{D d}(G)$ then

$$
\sum_{i=1}^{n} \rho_{i}^{2}=k+2\left(2 n^{2}-2 n-3 m\right)
$$

Proof. We know that in $A_{D d}(G)$ there are $2 m$ elements with 1 and $n(n-1)-2 m$ elements with 2 and hence corollary follows from the above theorem. 


\section{Bounds For Minimum Dominating Energy}

Similar to McClelland's [17] bounds for energy of a graph, bounds for $E_{D d}(G)$ are given in the following theorem.

Theorem 5.1. Let $G$ be a simple $(n, m)$ graph. If $D$ is the minimum dominating set and $P=\left|\operatorname{det} A_{D d}(G)\right|$ then

$$
\sqrt{(2 m+2 M+k)+n(n-1) P^{\frac{2}{n}}} \leq E_{D d}(G) \leq \sqrt{n(2 m+2 M+k)}
$$

where $k$ is a domination number.

Proof.

$$
\begin{aligned}
& \text { Cauchy Schwarz inequality is } \begin{aligned}
\left(\sum_{i=1}^{n} a_{i} b_{i}\right)^{2} & \leq\left(\sum_{i=1}^{n} a_{i}^{2}\right)\left(\sum_{i=1}^{n} b_{i}^{2}\right) \\
\text { If } a_{i}=1, b_{i}=\left|\rho_{i}\right| \text { then }\left(\sum_{i=1}^{n}\left|\rho_{i}\right|\right)^{2} & \leq\left(\sum_{i=1}^{n} 1\right)\left(\sum_{i=1}^{n} \rho_{i}^{2}\right) \\
& {\left[E_{D d}(G)\right]^{2} \leq n(2 m+2 M+k) \quad \text { [Theorem 4.1] } } \\
\Longrightarrow E_{D d}(G) & \leq \sqrt{n(2 m+2 M+k)}
\end{aligned}
\end{aligned}
$$

Since arithmetic mean is not smaller than geometric mean we have

$$
\begin{aligned}
\frac{1}{n(n-1)} \sum_{i \neq j}\left|\rho_{i} \| \rho_{j}\right| & \geq\left[\prod_{i \neq j}\left|\rho_{i}\right|\left|\rho_{j}\right|\right] \frac{1}{n(n-1)} \\
& =\left[\prod_{i=1}^{n}\left|\rho_{i}\right|^{2(n-1)}\right] \frac{1}{n(n-1)} \\
& =\left[\prod_{i=1}^{n}\left|\rho_{i}\right|\right]^{\frac{2}{n}} \\
& =\left|\prod_{i=1}^{n} \rho_{i}\right|^{\frac{2}{n}} \\
& =\left|\operatorname{det} A_{D d}(G)\right|^{\frac{2}{n}}=P^{\frac{2}{n}} \\
\therefore \sum_{i \neq j}\left|\rho_{i} \| \rho_{j}\right| \geq n(n-1) P^{\frac{2}{n}} &
\end{aligned}
$$




$$
\text { Now consider, } \begin{aligned}
{\left[E_{D d}(G)\right]^{2} } & =\left(\sum_{i=1}^{n}\left|\rho_{i}\right|\right)^{2} \\
& =\sum_{i=1}^{n}\left|\rho_{i}\right|^{2}+\sum_{i \neq j}\left|\rho_{i}\right|\left|\rho_{j}\right| \\
\therefore \quad\left[E_{D d}(G)\right]^{2} & \geq(k+2 m+2 M)+n(n-1) P^{\frac{2}{n}} \quad \text { [From (1)] } \\
\text { i.e., } E_{D d}(G) & \geq \sqrt{(k+2 m+2 M)+n(n-1) P^{\frac{2}{n}}}
\end{aligned}
$$

Theorem 5.2. If $\rho_{1}(G)$ is the largest minimum dominating distance eigenvalue of $A_{D d}(G)$, then

$$
\rho_{1}(G) \geq \frac{2 W(G)+k}{n}
$$

where $k$ is the domination number and $W(G)$ is the Wiener index of $G$.

Proof. Let $X$ be any nonzero vector. Then by [1], We have

$$
\rho_{1}\left(A_{D d}\right)=\max _{X \neq 0}\left\{\frac{X^{\prime} A_{D d} X}{X^{\prime} X}\right\} .
$$

Therefore,

$$
\rho_{1}\left(A_{D d}\right) \geq \frac{J^{\prime} A_{D d} J}{J^{\prime} J}=\frac{2 \sum_{i<j} d\left(v_{i}, v_{j}\right)+k}{n}=\frac{2 W(G)+k}{n}
$$

where $J$ is a unit matrix.

Lemma 5.3. Let $G$ be a graph of diameter 2 and $\rho_{1}(G)$ is the largest minimum dominating distance eigenvalue of $A_{D d}(G)$, then

$$
\rho_{1}(G) \geq \frac{2 n^{2}-2 m-2 n+k}{n}
$$

where $k$ is the domination number.

Proof. Let $G$ be a connected graph of diameter 2 and $d_{i}$ denotes the degree of vertex $v_{i}$. Clearly $i$-th row of $A_{d d}$ consists of $d_{i}$ one's and $n-d_{i}-1$ two's. By using Raleigh's principle, for $J=[1,1,1, \cdots, 1]$ we have

$\rho_{1}\left(A_{D d}\right) \geq \frac{J^{\prime} A_{D d} J}{J^{\prime} J}=\frac{\sum_{i=1}^{n}\left[d_{i} \times 1+\left(n-d_{i}-1\right) 2\right]+k}{n}=\frac{2 n^{2}-2 m-2 n+k}{n}$.

Similar to Koolen and Moulton's [15] upper bound for energy of a graph, upper bound for $E_{D d}(G)$ is given in the following theorem. 
Theorem 5.4. If $G$ is a $(m, n)$ graph with diameter 2 and $\frac{k+2 n^{2}-2 n-2 m}{n} \geq 1$ then

$E_{D d}(G) \leq \frac{k+2 n^{2}-2 n-2 m}{n}+\sqrt{(n-1)\left[k+4 n^{2}-4 n-6 m-\left(\frac{k+2 n^{2}-2 n-2 m}{n}\right)^{2}\right]}$.

Proof. Cauchy-Schwartz inequality is

$$
\left[\sum_{i=2}^{n} a_{i} b_{i}\right]^{2} \leq\left(\sum_{i=2}^{n} a_{i}^{2}\right)\left(\sum_{i=2}^{n} b_{i}^{2}\right)
$$

Put $a_{i}=1, b_{i}=\left|\rho_{i}\right|$, then

$$
\left(\sum_{i=2}^{n}\left|\rho_{i}\right|\right)^{2} \leq \sum_{i=2}^{n} 1 \sum_{i=2}^{n} \rho_{i}^{2}
$$

Then,

$$
\left[E_{D d}(G)-\rho_{1}\right]^{2} \leq(n-1)\left(k+4 n^{2}-4 n-6 m-\rho_{1}^{2}\right) .
$$

We have

$$
E_{D d}(G) \leq \rho_{1}+\sqrt{(n-1)\left(k+4 n^{2}-4 n-6 m-\rho_{1}^{2}\right)} .
$$

Let

$$
f(x)=x+\sqrt{(n-1)\left(k+4 n^{2}-4 n-6 m-x^{2}\right)} .
$$

For decreasing function, $f^{\prime}(x) \leq 0$ Then,

$$
1-\frac{x(n-1)}{\sqrt{(n-1)\left(k+4 n^{2}-4 n-6 m-x^{2}\right)}} \leq 0 .
$$

We have

$$
x \geq \sqrt{\frac{k+4 n^{2}-4 n-6 m}{n}} .
$$

Therefore, $f(x)$ is decreasing in

$$
\left[\sqrt{\frac{k+4 n^{2}-4 n-6 m}{n}}, \sqrt{k+4 n^{2}-4 n-6 m}\right] .
$$

Clearly,

$$
\sqrt{\frac{k+2 n^{2}-2 n-2 m}{n}} \in\left[\sqrt{\frac{k+4 n^{2}-4 n-6 m}{n}}, \sqrt{k+4 n^{2}-4 n-6 m}\right] .
$$

Since $\frac{k+2 n^{2}-2 n-2 m}{n} \geq 1$, we have

$$
\sqrt{\frac{k+2 n^{2}-2 n-2 m}{n}} \leq \frac{k+2 n^{2}-2 n-2 m}{n} \leq \rho_{1}(\text { by lema } 5.3)
$$


Therefore, $f\left(\rho_{1}\right) \leq f\left(\frac{k+2 n^{2}-2 n-2 m}{n}\right)$. Then,

$$
\begin{aligned}
E_{D d}(G) \leq & f\left(\rho_{1}\right) \\
\leq & f\left(\frac{k+2 n^{2}-2 n-2 m}{n}\right) \\
\leq & \frac{k+2 n^{2}-2 n-2 m}{n} \\
& +\sqrt{(n-1)\left[k+4 n^{2}-4 n-6 m-\left(\frac{k+2 n^{2}-2 n-2 m}{n}\right)^{2}\right]} .
\end{aligned}
$$

Bapat and S. Pati [2] proved that if the graph energy is a rational number then it is an even integer. Similar result for minimum dominating energy is given in the following theorem.

Lemma 5.5. Let $G$ be a graph with a minimum dominating set $D$. If the minimum dominating distance energy $E_{D d}(G)$ is a rational number, then $E_{D d}(G) \equiv|D|(\bmod$ 2).

Proof. Proof is similar to Theorem 5.4 of [19].

Acknowledgement. The authors thank the referees for their helpful comments and suggestions, which have improved the presentation of this paper.

\section{REFERENCES}

[1] Bapat, R.B., page No.32, Graphs and Matrices, Hindustan Book Agency, 2011.

[2] Bapat, R.B., and Pati, S., "Energy of a graph is never an odd integer", Bull. Kerala Math. Assoc., 1 (2011), 129-132.

[3] Bozkurt, S.B., Güngör, A.D., and Zhou, B., "Note on the distance energy of graphs", MATCH Commun. Math. Comput. Chem., 64 (2010), 129-134.

[4] Caporossi, G., Chasset, E., and Furtula, B., "Some conjectures and properties on distance energy", Les Cahiers du GERAD, G-2009-64 (2009), 1-7.

[5] Cvetković, C., and Gutman, I., (eds.), Applications of Graph Spectra, Mathematical Institution, Belgrade, 2009

[6] Cvetković, D., and Gutman, I., (eds.), Selected Topics on Applications of Graph Spectra, Mathematical Institute Belgrade, 2011.

[7] Graovac, A., Gutman, I., and Trinajstić, N., Topological Approach to the Chemistry of Conjugated Molecules, Springer, Berlin, 1977.

[8] Güngör, A.D., and Bozkurt, S.B., "On the distance spectral radius and distance energy of graphs", Lin. Multilin. Algebra, 59 (2011), 365-370.

[9] Gutman, I., "The energy of a graph", Ber. Math-Statist. Sekt. Forschungsz.Graz, 103 (1978), $1-22$.

[10] Gutman, I., Li, J., and Zhang, X., "Analysis of Complex Networks. From Biology to Linguistics", in Graph Energy, ed. by Dehmer, M., Emmert, F.-Streib, Wiley - VCH, Weinheim, 2009, 145-174.

[11] Gutman, I., "The energy of a graph: Old and New Results", in Algebraic Combinatorics and Applications, ed. by Betten et al., Springer, Berlin, 2001, 196-211. 
[12] Gutman, I., Polansky, O.E., Mathematical Concepts in Organic Chemistry, Springer, Berlin, 1986.

[13] Indulal, G., "Sharp bounds on the distance spectral radius and the distance energy of graphs", Lin. Algebra Appl., 430 (2009), 106-113.

[14] Indulal, G., Gutman, I., and Vijayakumar, A., "On distance energy of graphs", MATCH Commun. Math. Comput. Chem., 60 (2008), 461-472.

[15] Koolen, J.K., and Moulton. V., "Maximal energy graphs", Adv. Appl. Math., 26 (2001), 47-52.

[16] Liu, H., Lu, M., and Tian, F., "Some upper bounds for the energy of graphs", Journal of Mathematical Chemistry, 41:1 (2007)

[17] McClelland, B.J., "Properties of the latent roots of a matrix: The estimation of $\pi$-electron energies", J. Chem. Phys., 54 (1971), 640-643.

[18] Rajesh Kanna, M.R., Dharmendra, B.N., Shashi R., and Ramyashree, R.A., "Maximum degree energy of certain mesh derived networks", International Journal of Computer Applications, 78:8 (2013) 38-44.

[19] Rajesh Kanna, M.R., Dharmendra, B.N., and Sridhara, G., "Minimum Dominating Energy of a Graph", International Journal of Pure and Applied Mathematics, 85:4 (2013), 707-718.

[20] Rajesh Kanna, M.R., Dharmendra, B.N., and Sridhara, G., "Laplacian Minimum Dominating Energy of a Graph", International Journal of Pure and Applied Mathematics, 89:4 (2013), 565-581.

[21] Rajesh Kanna, M.R., Dharmendra, B.N., and Pradeep Kumar, R., "Minimum Covering Distance Energy of a Graph", Applied Mathematical Sciences, 7:111 (2013), 5525 - 5536.

[22] Ramane, H.S., Revankar, D.S., Gutman, I., Rao, S.B., Acharya, B.D., and Walikar, H.B., "Bounds for the distance energy of a graph", Kragujevac J. Math., 31 (2008), 5968. 